\title{
Optimal delivery of colorectal cancer follow-up care: improving patient outcomes
}

\author{
This article was published in the following Dove Press journal: \\ Patient Related Outcome Measures \\ 18 May 2015 \\ Number of times this article has been viewed
}

Mikaela L Jorgensen'

Jane M Young ${ }^{1,2}$

Michael J Solomon ${ }^{2,3}$

'Cancer Epidemiology and Services Research (CESR), Sydney School of Public Health, Sydney Medical School, University of Sydney, Sydney, NSW, Australia; ${ }^{2}$ Surgical Outcomes Research Centre (SOuRCe), Sydney Local Health District and University of Sydney, Sydney, NSW, Australia; ${ }^{3}$ Discipline of Surgery, University of Sydney, Sydney, NSW, Australia
Correspondence: Jane M Young Cancer Epidemiology and Services Research (CESR), Level 6, The Lifehouse (C39Z), I19-143 Missenden Road, Camperdown, NSW 2050, Australia Tel +6I 28627 I559

Email jane.young@sydney.edu.au
Abstract: Colorectal cancer (CRC) is the third most commonly diagnosed cancer worldwide. With population aging and increases in survival, the number of CRC survivors is projected to rise dramatically. The time following initial treatment is often described as a period of transition from intensive hospital-based care back into "regular life." This review provides an overview of recommended follow-up care for people with CRC who have been treated with curative intent, as well as exploring the current state of the research that underpins these guidelines. For patients, key concerns following treatment include the development of recurrent and new cancers, late and long-term effects of cancer and treatment, and the interplay of these factors with daily function and general health. For physicians, survivorship care plans can be a tool for coordinating the surveillance, intervention, and prevention of these key patient concerns. Though much of the research in cancer survivorship to date has focused on surveillance for recurrent disease, many national guidelines differ in their conclusions about the frequency and timing of follow-up tests. Most CRC guidelines refer only briefly to the management of side effects, despite reports that many patients have a range of ongoing physiological, psychosocial, and functional needs. Guidance for surveillance and intervention is often limited by a small number of heterogeneous trials conducted in this patient group. However, recently released survivorship guidelines emphasize the potential for the effectiveness of secondary prevention strategies, such as physical activity, to improve patient outcomes. There is also emerging evidence for the role of primary care providers and nurse coordinated care to support the transition and increase the cost-effectiveness of follow-up. The shift in focus from recurrence alone to the assessment and management of a range of survivorship issues will be important for ensuring that this growing group of patients achieves optimal outcomes.

Keywords: survivorship care, surveillance, secondary prevention, clinical practice guidelines

\section{Introduction}

Colorectal cancer (CRC) is the third most commonly diagnosed cancer worldwide, with almost 1.4 million new cases in $2012 .{ }^{1}$ It is commonly referred to as a disease of aging, as the median age of diagnosis is 70 years. ${ }^{2}$ The number of new cases is therefore projected to rise dramatically with the aging of the population that is currently occurring in nearly every country and region. ${ }^{3}$ As a result of improved screening, earlier detection, and increased treatment efficacy, relative survival from $\mathrm{CRC}$ has improved markedly in industrialized countries. ${ }^{4}$ Consequently, CRC is currently the third most prevalent cancer worldwide, with over 3.5 million survivors. ${ }^{1}$

Follow-up and survivorship care has become a major area of interest, largely since the release of a pivotal report by the United States Institute of Medicine in 2005. 
The report adopted the broad definition of a cancer survivor as any individual currently living with or affected by a diagnosis of cancer, including family, friends, and caregivers. In applying the definition, a focus was given to the relatively neglected period following initial treatment and prior to the development of recurrence or death. ${ }^{5}$ This period is often described as a time of transition from intensive hospitalbased care back into "regular life." While much of the research in cancer survivorship has traditionally focused on surveillance, those in the follow-up stage have a distinct range of physiological, psychosocial, and functional needs. A key challenge for clinicians is applying research findings and guideline recommendations to each individual patient, who will differ widely in their preexisting health status and in their response to cancer and its treatment.

Several excellent reviews and resources for survivorship care exist. ${ }^{6-9}$ This review will provide an overview of recommended follow-up care for people with CRC who have been treated with curative intent, as well as exploring the current state of the research that underpins these guidelines.

\section{Reasons for undertaking follow-up}

A key recommendation of the US Institute of Medicine (2005) report was that every cancer survivor be issued a survivorship care plan at the end of their initial cancer treatment. ${ }^{5}$ The plan aims to serve as both a record of a patient's clinical and initial treatment details, and as a plan for the coordination of care across key areas of post-treatment follow-up and survivorship (see Figure 1). For patients, key concerns following treatment include the development of recurrent and new cancers, late and long-term effects of cancer and treatment, and the interplay of these factors with daily function and general (non-cancer) health. For physicians, the care plan is a tool for coordinating the surveillance, intervention, and prevention of these key patient concerns.

\section{New or recurrent disease}

While the majority of patients with CRC present with local or locally advanced disease that can potentially be cured by

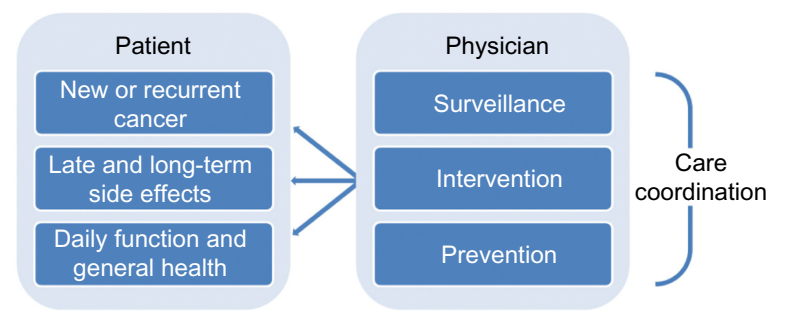

Figure I Elements of post-treatment follow-up care. surgical resection, up to $40 \%$ will experience recurrence. ${ }^{10}$ Of these recurrences, $80 \%$ occur in first 2-2.5 years, and $95 \%$ will occur by 5 years after treatment. ${ }^{11}$ Surveillance recommendations are therefore largely based around these time periods.

Recurrence can be local, regional, or systemic. The anatomy and physiology of the human pelvis essentially dictates the pattern of recurrence after treatment. Rectal cancers tend to recur locally or regionally because of the close proximity of the rectum to pelvic structures and organs and difficulties in achieving wide resection margins. ${ }^{12}$ Intraluminal recurrence, where malignant cells shed and implant around the surgical anastomosis, occurs in approximately $5 \%$ of rectal cancer patients. ${ }^{13}$ In colon cancer, recurrence is more likely to only occur at distant sites such as the liver and lungs. ${ }^{14}$

Two or more distinct primary carcinomas can also coexist around the time of diagnosis (synchronous), or can develop in a different part of the intestine up to several years after surgery (metachronous). These represent new non-recurrent cancers. Approximately 5\% of people with CRC will present with synchronous tumors, and the incidence of metachronous tumors is $2 \%$ at 5 years. ${ }^{15}$ Hereditary CRC syndromes, such as familial adenomatous polyposis and inflammatory bowel disease (ulcerative colitis) are predisposing factors in the development of multiple colorectal carcinomas. ${ }^{16}$

A history of CRC also places an individual at greater risk of developing a subsequent non-colorectal primary cancer, distinct from any risk of metastasis. This increased risk may be due to genetic susceptibilities, shared causative exposures like smoking, and/or as a result of anticancer treatment. ${ }^{17}$ Among CRC survivors, the most common sites for second primary cancers are in the breast, prostate, genitourinary tract, skin, and lung. ${ }^{18,19}$

\section{Late and long-term side effects}

Late effects are generally defined as problems that manifest after treatment has ended. Long-term effects are those that become apparent during treatment but may continue to persist for years afterwards. Late and long-term effects can occur as a consequence of surgery, chemotherapy, or radiotherapy. More generally, the diagnosis of cancer and its treatment can significantly affect long-term psychosocial health and daily function.

Late and long-term side effects of CRC surgery can include complications such as incisional or parastomal hernia, and bowel adhesions. ${ }^{20,21}$ Frequent or urgent bowel movements are also commonly reported in CRC. ${ }^{22}$ Longterm effects of pelvic radiotherapy for rectal cancer are less 
common with modern techniques, but typically involve anorectal and sexual function. ${ }^{23}$

The most common problems for cancer survivors are fatigue, anxiety and depression, and pain. ${ }^{24}$ Fatigue can persist long after treatment is complete. A populationbased data study conducted in the Netherlands reported that fatigue is nearly twice as common in CRC survivors than in an age- and sex-matched normative population. ${ }^{25}$ Peripheral neuropathy caused by the chemotherapy drug oxaliplatin may persist for a number of years for a small subset of patients. ${ }^{26}$ Sleep difficulties, and problems with concentration and memory, are also well documented ${ }^{27} \mathrm{As}$ many as $33 \%-96 \%$ of cancer survivors experience fears about progression or recurrence of disease, ${ }^{28}$ which can cause some patients to avoid surveillance or demand more intensive surveillance than advised. ${ }^{29}$

The exact prevalence and trajectory of various effects of cancer and its treatment are often hard to quantify, as longitudinal studies are rare and few studies differentiate between the effects of cancer and the effects of aging. ${ }^{30}$ However, most cancer survivors report having a high quality of 1 life $\mathrm{e}^{31}$ and being in good general health 5 years or more after treatment. ${ }^{32}$ Physical wellbeing is generally improved by 3 or more years after diagnosis for most CRC survivors. ${ }^{6}$

\section{Daily function and general health}

Clinical and psychosocial side effects of cancer and its treatment can affect an individual's ability to function in everyday life. Gastrointestinal cancer survivors, including those with CRC, have been found to be at higher risk for unemployment than healthy adults. ${ }^{33}$ This is a key issue, as work after a cancer diagnosis provides financial security, forms a central basis for self-identity and self-esteem, and helps to maintain social relationships. ${ }^{34}$ The presence of a stoma has also been associated with increased financial worries as well as diminished body image, ${ }^{35}$ with survivors being more likely to report negative feelings about body appearance if they have a stoma. ${ }^{36}$ Although the presence of a stoma has been reported to negatively impact social functioning at 1 year after diagnosis, ${ }^{37}$ results of follow-up at more than 2 years after diagnosis suggest that a permanent stoma does not have a long-lasting impact on social functioning. ${ }^{38}$

Cancer survivors are at increased risk for long-term morbidity and premature mortality, related directly to the cancer itself, to preexisting comorbidities, and to exposure to therapy. For example, patients with CRC who have diabetes have an increased risk of recurrence as well as poorer short- and long-term mortality. ${ }^{39}$ Issues of CRC survivorship may be further complicated by advancing age, as the prevalence of chronic conditions increases and functional reserves are depleted. Having a greater number of comorbidities can interact with cancer status to produce a greater degree of ongoing symptom burden in a dose-dependent manner. ${ }^{40}$ Pain, fatigue, insomnia, and mood disturbance may occur in a cluster and negatively influence older patients' ability to perform normal daily activities. ${ }^{41}$

\section{What are the current guidelines for follow-up care in CRC?}

This section examines the broad recommendations from ten major national guidelines for follow-up and survivorship care in CRC that have been issued over the last 5 years. ${ }^{11,42-51}$ The majority of guidelines advise that their recommendations apply only to those who have received a curative resection for stage II or stage III disease, typically citing the lack of data to provide evidence-based guidance for stage I or metastatic disease. ${ }^{11}$ Cancer Care Ontario suggests that extrapolating recommendations to Stage I patients should be left to the discretion of the health care provider. ${ }^{42}$ Some guidelines suggest that it is reasonable to apply recommendations to all patients who have been curatively treated and who would be candidates for further aggressive treatment. ${ }^{48}$ With better treatments, this will increasingly include a proportion of patients with resectable metastatic disease.

A summary of recommendations for each of the guidelines is documented in Table 1, and an example surveillance schedule based on the guidelines is presented in Table 2 . While national guidelines differ in their conclusions about the frequency and timing of follow-up surveillance, there are a number of common recommendations across guidelines for the follow-up care of patients with CRC:

- History and physical examination - a clinical encounter with a physician at regular intervals to highlight symptoms that may suggest cancer recurrence, and digital rectal examination for select patients with rectal cancer.

- Carcinoembryonic antigen (CEA) testing, at each follow-up visit. CEA is a protein that is elevated in the blood of patients in a number of cancers including CRC, and can indicate disease recurrence before clinical signs and symptoms are apparent.

- Colonoscopy/proctoscopy/rectosigmoidoscopy, to visualize metanchronous CRC or polyps and anastomotic recurrence. If colonoscopy could not be performed 
Table I Summary of recommendations from national guidelines on the follow-up care of patients with CRC

\begin{tabular}{|c|c|c|c|c|}
\hline $\begin{array}{l}\text { Cancer Care } \\
\text { Ontario } 42, a \\
\text { Stage II-III with } \\
\text { NED }\end{array}$ & $\begin{array}{l}\text { National Comprehensive } \\
\text { Cancer Network }{ }^{\circledR} \\
\left(\mathbf{N C C N}^{\circledR}\right)^{43,44,104, b} \\
\text { Any stage with NED }\end{array}$ & $\begin{array}{l}\text { ASCO }{ }^{\prime \prime, c} \\
\text { Stage II-III and } \\
\text { candidate } \\
\text { for aggressive Tx }\end{array}$ & $\begin{array}{l}\text { ESMO (colon) })^{45, d} \\
\text { Not advanced } \\
\text { stage }\end{array}$ & $\begin{array}{l}\text { ESMO (rectal) } \\
\text { No staging } \\
\text { specified }\end{array}$ \\
\hline e $6 \mathrm{~m}$ for $5 y$ & $\begin{array}{l}\text { e } 3-6 \mathrm{~m} \text { for } 2 y \text {, then } \\
\text { e } 6 \mathrm{~m} \text { til } 5 y^{i}\end{array}$ & e $3-6 m$ for $5 y$ & $\begin{array}{l}\text { e } 3-6 \mathrm{~m} \text { for } 3 y \\
\text { then e } 6-12 \mathrm{~m} \\
\text { until } 5 \mathrm{y}\end{array}$ & $\begin{array}{l}\text { e } 6 \mathrm{~m} \text { for } 2 \mathrm{y} \text {; } \\
\text { DRE: e } 3-6 \mathrm{~m} \text { for } 3 \mathrm{y} \\
\text { then e } 6-12 \mathrm{~m} \\
\text { until } 5 \mathrm{y}\end{array}$ \\
\hline e $6 \mathrm{~m}$ for $5 y$ & $\begin{array}{l}\text { e } 3-6 \mathrm{~m} \text { for } 2 y \text {, then } \\
\text { e } 6 \mathrm{~m} \text { til } 5 \mathrm{y}^{\mathrm{i}, \mathrm{ii}}\end{array}$ & e $3-6 m$ for $5 y^{v i}$ & $\begin{array}{l}\text { e } 3-6 \mathrm{~m} \text { for } 3 y \text {, } \\
\text { then e } 6-12 \mathrm{~m} \\
\text { until } 5 \mathrm{y}\end{array}$ & $\begin{array}{l}\text { Other tools for } \\
\text { suspicious symptoms } \\
\text { only }\end{array}$ \\
\hline $\begin{array}{l}\text { At } 12 \mathrm{~m} \text {, then } \\
\text { e } 5 \mathrm{y} \text { if normal }\end{array}$ & $\begin{array}{l}@ 12 \text { m or @ 3-6 m } \\
\text { post resection if not } \\
\text { preoperatively, }\end{array}$ & $\begin{array}{l}\text { At } 12 \mathrm{~m} \text { or after } \\
\text { adjuvant } T x \text { if not } \\
\text { at } D x \text {, then e } 5 y\end{array}$ & $\begin{array}{l}\text { At } 12 \mathrm{~m} \text {, then } \\
\text { e } 3-5 \mathrm{y}\end{array}$ & $\begin{array}{l}\text { Within } 12 \mathrm{~m} \text { if not } \\
\text { at } \mathrm{Dx} \text {, then e } 5 \mathrm{y} \\
\text { until age } 75\end{array}$ \\
\hline
\end{tabular}

\begin{tabular}{|c|c|c|c|c|}
\hline & & & & \\
\hline $\begin{array}{l}\text { Proctoscopyl } \\
\text { rectosigmoidoscopy } \\
\text { for rectal cancer }\end{array}$ & $\begin{array}{l}\text { Rectosigmoidoscopy: } \\
\text { e } 6 \mathrm{~m} \text { for } 2-5 \text { y } \\
\text { if no pelvic radiation }\end{array}$ & Not recommended & $\begin{array}{l}\text { Rectosigmoidoscopy: } \\
\text { e } 6 \mathrm{~m} \text { for } 2-5 \text { y } \\
\text { if no pelvic radiation }\end{array}$ & \\
\hline $\begin{array}{l}\text { Abdominal and } \\
\text { chest } \mathrm{CT}\end{array}$ & e $12 \mathrm{~m}$ for $3 y^{i}$ & $\begin{array}{l}\text { e } 12 \mathrm{~m} \text { for up to } 5 \mathrm{y} \text { if } \\
\text { high risk, }{ }^{\mathrm{i}, \mathrm{iv}} \text {; e } 3-6 \mathrm{~m} \text { for } 2 \mathrm{y} \text {, } \\
\text { then e } 6-12 \mathrm{~m} \text { til } 5 \mathrm{y} \\
\text { (stage IV colon) }\end{array}$ & e $12 \mathrm{~m}$ for $3 y^{\mathrm{vii}}$ & $\begin{array}{l}\text { e } 6-12 \mathrm{~m} \text { for } 3 \text { y if } \\
\text { higher risk; } \\
\text { CEUS can substitute } \\
\text { for abdominal CT }\end{array}$ \\
\hline Pelvic CT & $\begin{array}{l}\text { e } 12 \mathrm{~m} \text { for } 3 \text { y } \\
\text { (rectal) }\end{array}$ & $\begin{array}{l}\text { e } 12 \mathrm{~m} \text { for up to } 5 \mathrm{y} \text { if } \\
\text { high risk, }{ }^{\mathrm{i}, \mathrm{iv}} \text {; e } 3-6 \mathrm{~m} \text { for } 2 \mathrm{y} \text {, } \\
\text { then e } 6-12 \mathrm{~m} \text { til } 5 \mathrm{y} \\
\text { (stage IV colon) }\end{array}$ & $\begin{array}{l}\text { eg, e } 12 \text { m for } 3-5 \text { y } \\
\text { (rectal) viii }\end{array}$ & \\
\hline $\begin{array}{l}\text { Other } \\
\text { recommendations }\end{array}$ & $\begin{array}{l}\text { Reasonable to } \\
\text { counsel on ideal } \\
\text { bodyweight, physical } \\
\text { activity, diet; FOBT } \\
\text { is not recommended }\end{array}$ & $\begin{array}{l}\text { Monitor and manage bowel } \\
\text { and urogenital late effects; } \\
\text { Counsel for healthy lifestyle; } \\
\text { Cancer screening (breast, } \\
\text { prostate) as average risk; } \\
\text { Additional health monitoring } \\
\text { and immunizations as } \\
\text { indicated; PET scans } \\
\text { not recommended }\end{array}$ & $\begin{array}{l}\text { Reasonable to counsel } \\
\text { on healthy bodyweight, } \\
\text { diet, physical activity; } \\
\text { PET scans are not } \\
\text { recommended }\end{array}$ & $\begin{array}{l}\text { General medical and } \\
\text { preventative health } \\
\text { issues are equal in } \\
\text { importance to the } \\
\text { care of cancer }\end{array}$ \\
\hline
\end{tabular}

Notes: *Refers to separate guidelines for survivor models of care; ****from ESMO 2012 iNot recommended for stage I colon cancer; ilf candidate for further intervention; iiirecommend e I-2 y for patients with $\mathrm{HNPCC}^{3}$; ivstage III or II with lymphatic/venous invasion or poorly differentiated tumors; vstage III or II with lymphatic/venous invasion or poorly differentiated tumors; vimore frequent if higher risk; viic consider e 6-12 m if higher risk; viiclinician to determine frequency considering risk status;

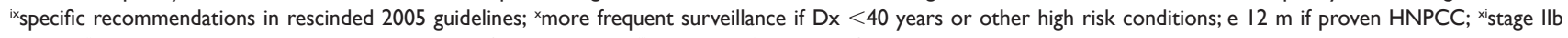

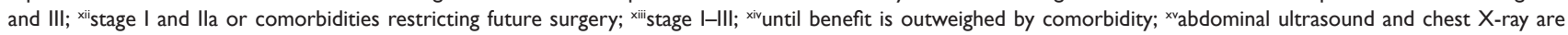
acceptable. ${ }^{a}$ Copyright (C) 2012, Cancer Care Ontario. Adapted from Earle C, Annis R, Sussman J, et al. Follow-up Care, Surveillance Protocol, and Secondary Prevention Measures for Survivors of Colorectal Cancer. Toronto: Cancer Care Ontario; 201242. ${ }^{6}$ Referenced with permission from the NCCN Clinical Practice Guidelines in Oncology (NCCN Guidelines $^{\circledR}$ ) for Colon Cancer V.2.20I5. Copyright (C) National Comprehensive Cancer Network, Inc 20I4. All rights reserved. Accessed [March 20, 20I5]. To view the most recent and complete version of the guideline, go online to NCCN.org. NATIONAL COMPREHENSIVE CANCER NETWORK ${ }^{\circledR}$, NCCN ${ }^{\circledR}$, NCCN GUIDELINES ${ }^{\circledR}$, and all other NCCN Content are trademarks owned by the National Comprehensive Cancer Network, Inc. ${ }^{43}$ Referenced with permission from the NCCN Clinical Practice Guidelines in Oncology (NCCN Guidelines ${ }^{\circledR}$ ) for Rectal Cancer V.2.20I5. Copyright (C) National Comprehensive Cancer Network, Inc 20I4. All rights reserved. Accessed [March 20,20I5].To view the most recent and complete version of the guideline, go online to NCCN.org. NATIONAL COMPREHENSIVE CANCER NETWORK ${ }^{\circledR}$, $\mathrm{NCCN}^{\circledR}, \mathrm{NCCN}$ GUIDELINES ${ }^{\circledR}$, and all other NCCN Content are trademarks owned by the National Comprehensive Cancer Network, Inc. ${ }^{44}$ Referenced with permission from the NCCN Clinical Practice Guidelines in Oncology (NCCN Guidelines ${ }^{\circledR}$ ) for Genetic/Familial High-Risk Assessment: Colorectal V.2.20I4. Copyright $\odot$ National Comprehensive Cancer Network, Inc 2014. All rights reserved. Accessed [March 20, 20I5]. To view the most recent and complete version of the guideline, go online to NCCN.org. NATIONAL COMPREHENSIVE CANCER NETWORK ${ }^{\circledR}$, NCCN ${ }^{\circledR}$, NCCN GUIDELINES ${ }^{\circledR}$, and all other NCCN Content are trademarks owned by the National Comprehensive Cancer Network, Inc. ${ }^{104}$ cCopyright (C) 20I3, American Society of Clinical Oncology. Adapted with permission; from Meyerhardt JA, Mangu PB, Flynn PJ, et al. 


\begin{tabular}{|c|c|c|c|c|}
\hline $\begin{array}{l}\text { NICE }^{47, \mathrm{f}} \\
\text { Curatively } \\
\text { resected }\end{array}$ & $\begin{array}{l}\text { Cancer Council Australia }{ }^{48, g} \\
\text { Curatively resected and fit } \\
\text { for further intervention }\end{array}$ & $\begin{array}{l}\text { NZGG }{ }^{49, \mathrm{~h}} \\
\text { All resected }\end{array}$ & $\begin{array}{l}\text { BSG } / A C G B I^{50, j} \\
\text { Curatively } \\
\text { treated }\end{array}$ & $\begin{array}{l}\text { JSCCR } \\
\text { Curatively } \\
\text { resected stage I-III }\end{array}$ \\
\hline $\begin{array}{l}\text { Start clinic visits } \\
4-6 \text { weeks after Tx }\end{array}$ & $\begin{array}{l}\text { DRE: e } 6 \mathrm{~m} \text { for } 2-3 \text { y if local } \\
\text { excision or ULAR (rectal) }\end{array}$ & $\begin{array}{l}\text { e } 6 \mathrm{~m} \text { for } 3 \mathrm{y} \text {, then e } 12 \mathrm{~m} \text { until } \\
5 \mathrm{y} \text { if high risk:; } \text { e } 12 \mathrm{~m} \text { for } 5 \mathrm{y} \\
\text { if low risk }{ }^{\times i i} \text { (colon) }\end{array}$ & & $\begin{array}{l}\text { e } 3 \mathrm{~m} \text { for } 3 \mathrm{y} \text {, then e } 6 \mathrm{~m} \\
\text { until } 5 \mathrm{y} \text {; DRE: e } 6 \mathrm{~m} \text { for } 3 \mathrm{y}\end{array}$ \\
\hline Min e $6 \mathrm{~m}$ for $3 y$ & $\begin{array}{l}\text { Intensive follow-up } \\
\text { recommended } \\
\text { including CEA }\end{array}$ & $\begin{array}{l}\text { e } 6 \mathrm{~m} \text { for } 3 \mathrm{y} \text {, then e } 12 \mathrm{~m} \text { until } \\
5 \mathrm{y} \text { if high risk; }{ }^{\times i} \text { e } 12 \mathrm{~m} \text { for } \\
5 \mathrm{y} \text { if low risk }{ }^{\times i i} \text { (colon) }\end{array}$ & & $\begin{array}{l}\text { e } 3 \mathrm{~m} \text { for } 3 \mathrm{y} \\
\text { then e } 6 \mathrm{~m} \text { until } 5 \mathrm{y}\end{array}$ \\
\hline \multirow[t]{2}{*}{$\begin{array}{l}\text { At } 12 \mathrm{~m} \text {, then e } 5 \mathrm{y} \text { if } \\
\text { normal }\end{array}$} & $\begin{array}{l}\text { At } 12 \mathrm{~m} \text { or at } 3-6 \mathrm{~m} \text { after } \\
\text { resection if not perioperatively, } \\
\text { then at } 6 \mathrm{y} \text { if normal }\end{array}$ & $\begin{array}{l}\text { Before surgery or within } 12 \mathrm{~m} \text {, } \\
\text { then e } 3-5 \text { y (rectal or low risk } \\
\text { colon) })^{\times i i}\end{array}$ & e $5 y^{x i v}$ & $\begin{array}{l}\text { At } 12 \mathrm{~m} \text {, then at } 3 \mathrm{y} \\
\text { (colon); e } 12 \mathrm{~m} \text { for } 3 \mathrm{y} \\
\text { (rectal) }\end{array}$ \\
\hline & $\begin{array}{l}\text { Rigid or flexible proctoscopy } \\
\text { and/or rectal ultrasound: e } 6 \mathrm{~m} \\
\text { for } 2-3 \text { y if local excision or } \\
\text { ULAR }\end{array}$ & $\begin{array}{l}\text { DRE, proctoscopy, or } \\
\text { sigmoidoscopy: at } 3,6 \text {, and } \\
12 \mathrm{~m} \text { and at } 2 y\end{array}$ & & \\
\hline Min 2 scans in first $3 y$ & $\begin{array}{l}\text { Intensive follow-up } \\
\text { recommended including } \\
\text { imagingix }\end{array}$ & Liver CT between I and $3 y^{x i i i}$ & $\begin{array}{l}\text { Liver CT: } \\
\text { within } 2 \text { y }\end{array}$ & $\begin{array}{l}\text { e } 6 \mathrm{~m} \text { for } 3 \mathrm{y} \text {, then e } 12 \mathrm{~m} \\
\text { until } 5 \text { y (stage I-II); e } 6 \mathrm{~m} \text { for } \\
5 \text { y }(\text { stage III })^{\mathrm{xv}}\end{array}$ \\
\hline Min 2 scans in first $3 y$ & $\begin{array}{l}\text { Intensive follow-up } \\
\text { recommended including } \\
\text { imaging' }\end{array}$ & & & $\begin{array}{l}\text { e } 6 \mathrm{~m} \text { for } 3 \mathrm{y} \text {, then e } 12 \mathrm{~m} \\
\text { until } 5 \text { y (stage I-II); e } 6 \mathrm{~m} \text { for } \\
5 \text { y (stage III) (rectal) }\end{array}$ \\
\hline
\end{tabular}

Multidisciplinary team to direct and may involve follow-up in primary care; give written information outlining follow-up plan

\section{BSG/ACGB| $\left.\right|^{50, j} \quad J^{S C C R}{ }^{51, k}$ \\ Curatively Curatively \\ treated resected stage I-III}

e $3 \mathrm{~m}$ for $3 \mathrm{y}$, then e $6 \mathrm{~m}$

until 5 y; DRE: e $6 \mathrm{~m}$ for $3 y$

e $3 \mathrm{~m}$ for $3 y$,

then e $6 \mathrm{~m}$ until $5 \mathrm{y}$

At $12 \mathrm{~m}$, then at $3 \mathrm{y}$

(colon); e $12 \mathrm{~m}$ for $3 y$
Offer jargon-free verbal and written information on managing bowel side effects, available support groups, online resources
Offer colonoscopic educational advice and/or music to reduce patient anxiety and discomfort

Follow-up care, surveillance protocol, and secondary prevention measures for survivors of colorectal cancer: American Society of Clinical Oncology clinical practice guideline

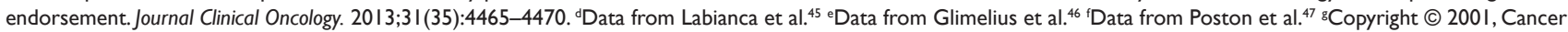
Council Australia.Adapted with permission; from Cancer Council Australia Colonoscopy Surveillance Working Party. Clinical Practice Guidelines for Surveillance Colonoscopy - In Adenoma Follow-Up; Following Curative Resection of Colorectal Cancer; and for Cancer Surveillance in Inflammatory Bowel Disease. Sydney: Cancer Council Australia; 20 I I. ${ }^{48}$ hCopyright (C) 200I, New Zealand Guidelines Group. Adapted with permission; from Clinical Practice Guidelines for the Management of Early Colorectal Cancer. Wellington: New Zealand Guidelines Group; 201 I. ${ }^{49}$ iData from Cairns et al. ${ }^{50}$; ${ }^{\mathrm{k}}$ Data from Watanabe et al. ${ }^{51}$

Abbreviations: CEA, carcinoembryonic antigen; CEUS, contrast-enhanced ultrasound; CRC, colorectal cancer; CT, computed tomography; DRE, digital rectal examination; Dx, diagnosis; e, every; FOBT, fecal occult blood testing; HNPCC, hereditary nonpolyposis CRC; $m$, months; min, minimum; PET, positron emission tomography; Tx, treatment; $y$, years; NED, no evidence of disease; ASCO,American Society of Clinical Oncology; ESMO, European Society of Medical Oncology; ULAR, ultra-low anterior resection. 
Table 2 Example schedule for surveillance following curative treatment for colorectal cancer

\begin{tabular}{|c|c|c|c|c|c|c|c|c|c|c|c|c|c|c|c|c|c|c|c|c|}
\hline \multirow[t]{2}{*}{ Months after treatment } & \multicolumn{4}{|c|}{ I year } & \multicolumn{4}{|c|}{2 years } & \multicolumn{4}{|c|}{3 years } & \multicolumn{4}{|c|}{4 years } & \multicolumn{4}{|c|}{5 years } \\
\hline & 3 & 6 & 9 & 12 & 15 & 18 & 21 & 24 & 27 & 30 & 33 & 36 & 39 & 42 & 45 & 48 & 51 & 54 & 57 & 60 \\
\hline History, physical, CEA & $(\mathrm{x})$ & $x$ & $(\mathrm{x})$ & $x$ & $(x)$ & $x$ & $(\mathrm{x})$ & $x$ & $(x)$ & $x$ & $(\mathrm{x})$ & $x$ & & $x$ & & $x$ & & $x$ & & $x$ \\
\hline Colonoscopy & $(\mathrm{x})$ & & & $x$ & & & & & & & & $x$ & & & & & & & & \\
\hline Abdominal/chest CT & & & & $x$ & & & & $x$ & & & & $x$ & & & & & & & & \\
\hline Procto/rectosigmoidoscopy* & & $x$ & & $x$ & & $x$ & & $x$ & & $(x)$ & & $(x)$ & & $(x)$ & & $(x)$ & & $(x)$ & & $(x)$ \\
\hline Pelvic CT* & & & & $x$ & & & & $x$ & & & & $x$ & & & & $(x)$ & & & & $(x)$ \\
\hline
\end{tabular}

Notes: *For rectal cancer only; $\mathrm{x}=$ recommended; $(\mathrm{x})=$ recommended by some guidelines only.

Abbreviations: CEA, carcinoembryonic antigen; $\mathrm{CT}$, computed tomography.

preoperatively due to obstruction, one should be carried out soon after initial treatment to identify any synchronous tumors.

- Computed tomography (CT) scans of chest/abdomen/ pelvis, primarily to detect distant metastatic disease in the lung or liver, and locoregional pelvic recurrence in select patients with rectal cancer.

- Positron emission tomography and fecal occult blood testing - not routinely recommended.

- Care coordination - reasonable to discharge care to a nurse or community physician with a treatment summary and surveillance plan.

- Other common recommendations:

o Monitor and manage late and long-term effects on bowel function

o Reasonable to counsel patients on preventative health measures such as healthy weight, diet, and physical activity.

\section{Surveillance}

Most of the research and evidence after initial treatment for $\mathrm{CRC}$ has focused on surveillance for the early identification of recurrent disease. While it may be intuitive that earlier detection will lead to better outcomes, this assumption requires that a number of conditions are met. For any surveillance program to be meaningful, recurrence would have to be detected before it is symptomatic, earlier detection would have to lead to effective treatment and better outcomes, and patients would have to be willing and able to undergo further treatment. ${ }^{52}$

There is evidence that each of CEA testing, colonoscopy, and $\mathrm{CT}$ imaging lead to increased detection of asymptomatic recurrence and a higher rate of surgery for recurrence. ${ }^{53}$ Nearly all guidelines recommend "intensive" follow-up based on a combination of these surveillance strategies. The two most recent meta-analyses of randomized controlled trials of follow-up after curative resection report significant improvements in all-cause mortality with more intensive follow-up. ${ }^{54,55}$
However, neither of these meta-analyses found that intensive follow-up improved cancer-specific survival. More recently, a randomized controlled trial conducted in the UK reported that there was little difference in overall survival between a group allocated to minimum follow-up following curative treatment for CRC and those allocated to CEA alone, CT alone, or CEA $+\mathrm{CT}^{56}$ A systematic review completed in 2011 concluded that the literature on the efficacy of surveillance in CRC was inconclusive due to small sample sizes and heterogeneity in the frequency of surveillance. ${ }^{57}$ An overlap in what is considered intensive and non-intensive strategies between randomized controlled trials is a likely contributor to the discrepancy in guideline recommendations for frequency.

Some national guidelines note that surveillance measures should only apply to patients who are amenable for resection of recurrent disease $\mathrm{e}^{58}$ or who do not have severe comorbid conditions that would preclude further aggressive treatment. ${ }^{11}$ However, the effectiveness of surgery and systemic therapy following detection of recurrence is not well explored. While those receiving surgery for recurrent colon cancer have been reported to have a 5 -year survival of up to $30 \%,{ }^{12}$ the prognosis for pelvic recurrent rectal cancer is dismal, ${ }^{59}$ though can be improved by radical surgery such as pelvic exenteration. ${ }^{60,61}$ Despite clear differences in natural history of recurrence by tumor site, most guidelines only issue a site-specific recommendation for pelvic CT. The National Comprehensive Cancer Network (NCCN), who produce separate guidelines for colon and rectal cancer, note the overall dearth of evidence for surveillance in rectal cancer. ${ }^{44}$ Rectosigmoid cancer accounts for nearly $9 \%$ of CRC cases; however, follow-up strategies for these patients are only discussed in the JSCCR (Japanese Society for Cancer of the Colon and Rectum) guidelines. ${ }^{51}$ In addition, European guidelines state that follow-up should depend on a number of factors including perioperative treatment ${ }^{58}$ which will differ by cancer site as well as other clinical characteristics.

Consequently, a number of guidelines suggest tailoring surveillance plans based on the presumed risk of recurrence. 
It may be that patient groups who would benefit from more intensive surveillance strategies are obscured within large, heterogeneous study populations. ${ }^{62}$ Although stratifying patients by risk would likely reduce costs and spare certain patients some of the morbidity associated with surveillance, there is little research evidence in this area. ${ }^{63}$ The NCCN and Cancer Council Australia suggest more intensive follow-up for patient groups such as those with family history and suspected hereditary nonpolyposis CRC. ${ }^{43,48}$ However, as pointed out in a letter to the editor response to the American Society of Clinical Oncology (ASCO) guidelines, studies have consistently shown that cancer patients with the highest risk of recurrence, especially because of node positivity, are the least likely to be cured. ${ }^{64}$ It is also plausible that patients at greater risk of recurrence as a result of suboptimal initial cancer treatment, for example, may also be at increased risk of poorer follow-up care and outcomes.

Cost-effectiveness goes largely unaddressed in most of the guidelines, though it is likely a major cause of difference in follow-up practices between regions. $\mathrm{Ku}$ et $\mathrm{al}^{65}$ document a series of recommendations for the application of follow-up strategies in Asian countries with different levels of health care resources and economic development. The Ontario guidelines suggest that abdominal ultrasound and chest X-ray can be substituted if local resources preclude the use of CT. ${ }^{42}$ As part of the Australian guidelines, an analysis of the estimated additional costs of surveillance colonoscopies with more intensive guidelines was performed, as well as a review of 18 existing economic studies. ${ }^{48}$ This review concluded that there is some evidence that more frequent or earlier follow-up is costeffective compared with strategies with minimal follow-up. In contrast, National Institute for Health and Care Excellence (NICE) guidelines place a greater emphasis on personal costs, with a recommendation to cease regular follow-up when the patient and the health care professional agree that the likely benefits no longer outweigh the risks of further tests. ${ }^{47}$ The effects of CRC surveillance in terms of somatic complications, negative psychosocial consequences, and the impact of false positive or false negative tests, are outlined in a recent systematic review. ${ }^{66}$ In particular, the review highlights the risks of colonoscopy-related colonic perforation and post-procedure bleeding, the limited evidence that CRC follow-up improves quality of life among survivors, and the potential for increased long-term anxiety following false positive screening results.

\section{Intervention and prevention}

Most of the CRC clinical practice guidelines refer only briefly to the management of physical and psychosocial side effects or the prevention of recurrent and new cancers. However, there is growing awareness that optimal cancer follow-up care involves more than surveillance tests. Several symptom-based guidelines for follow-up care now exist, as well as general survivorship guidelines for care across all cancer types.

In April of this year (2014), ASCO issued three clinical practice guidelines on the prevention and management of symptoms that affect many cancer survivors - chemotherapyinduced peripheral neuropathy, ${ }^{67}$ fatigue, ${ }^{68}$ and anxiety and depression. ${ }^{69}$ While a number of other organizations have published guidelines for the psychosocial care of cancer patients, ${ }^{70}$ bone health, ${ }^{71}$ and cancer pain, ${ }^{72}$ these do not focus on follow-up care. A pan-Canadian guideline reviewing survivorship services for adult cancer populations was released in $2011 .{ }^{73}$ However, the NCCN issued the first comprehensive adult survivorship guidelines in $2013 .{ }^{74}$ These drew on previous NCCN symptom-based publications and were designed to provide guidance for screening, evaluation, and treatment across the range of survivor health needs.

The current NCCN survivorship guidelines recommend that all survivors should be periodically screened for symptoms related to cancer and cancer treatment, with appropriate follow-up care as clinically indicated, while noting that not all issues can be addressed at every visit. ${ }^{30} \mathrm{~A}$ number of validated tools for screening of long-term and late physical and psychosocial effects are suggested, including the SF-SUNS (Short Form Survivor Unmet Needs Survey) ${ }^{75}$ and the QLACS (Quality of Life in Adult Cancer Survivors). ${ }^{76}$ However, it is also noted that screening is not an effective strategy unless there is adequate follow-up referral and access to treatment. For example, a recent review reported that screening for distress led to improved patient outcomes only where trials were linked with mandatory referral or intervention. ${ }^{77}$

There is evidence from randomized controlled trials for the effectiveness of interventions to lessen symptoms such as depression, fatigue, pain, and sleep disorders in cancer survivors. ${ }^{78}$ Findings from meta-analyses indicate that exercise training provides a small overall reduction in depressive symptoms $^{79}$ and that there is some evidence to support the use of mindfulness-based therapy for anxiety and depression. ${ }^{80}$ Data supporting the efficacy of increased physical activity for reducing fatigue are strong. ${ }^{81}$ Results of psychosocial interventions for fatigue are mixed, though promising for some approaches including cognitive-behavioral and supportiveexpressive therapy. ${ }^{82}$ Both exercise and psychosocial interventions may also assist with sleep disturbances in survivors. ${ }^{83,84}$

However, the evidence base supporting screening and intervention are limited in a number of areas of survivorship. 
There is no screening tool with adequate sensitivity for detecting cancer-associated cognitive dysfunction in asymptomatic cancer survivors, and there is a lack of quality data for interventions in cancer survivors who complain of cognitive dysfunction. ${ }^{30}$ The evidence for treating female sexual dysfunction in survivorship populations, and for reducing pain with psychosocial and behavioral interventions, is also limited..$^{30}$ Overall, intervention trials in survivorship populations tend to be few, small, and/or heterogeneous. For example, a single larger randomized trial forms the basis for the lone clinical recommendation by the ASCO in the treatment of peripheral neuropathy. ${ }^{67}$ While few studies have reported an intervention specifically designed to reduce the commonly reported fear of cancer recurrence, a multicenter randomized controlled trial is currently underway in Australia. ${ }^{85}$

The NCCN state that their recommendations for survivorship care are based on evidence from randomized controlled trials, but that extrapolation from other populations was deemed appropriate where evidence for survivorship populations was lacking. ${ }^{30}$ The majority of trials continue to be conducted on patients who are receiving treatment or who are in the immediate post-treatment period. Jacobsen ${ }^{86}$ argues that overall conclusions of systematic reviews of psychosocial interventions for cancer patients are of limited value to everyday clinical practice as a result of heterogeneity of both interventions and patient characteristics. Furthermore, while there is a growing evidence base for the effectiveness of rehabilitation targeting single symptoms, the evidence for multidimensional interventions is scarce and dominated by breast cancer studies. ${ }^{87}$ It is likely that a combination of interventions, adjusted to the survivor's individual needs, is required to improve quality of life.

In the area of secondary prevention, most of the CRC practice guidelines state that their recommendations are based on lower level evidence. Nevertheless, it is commonly suggested that patients should be counseled on maintaining a healthy bodyweight, being physically active, eating a healthy diet, and smoking cessation. Evidence from observational studies suggests that a low-fat, high-fiber diet might be protective against cancer recurrence and progression. ${ }^{88}$ A systematic review and meta-analysis in breast and CRC determined that physical activity performed before or after a cancer diagnosis can reduce mortality risk. ${ }^{89}$ The mechanism of benefit from diet and physical activity likely relates to bodyweight, with excess weight being a risk factor which is modifiable through lifestyle. ${ }^{88}$ Preliminary evidence from randomized controlled trials suggests that exercise may also result in beneficial changes in the circulating level of insulin, inflammation, and possibly immunity. ${ }^{90}$ In addition, smoking cessation has the potential to improve prognosis, given that continued smoking after CRC diagnosis has been linked to poorer survival. ${ }^{91}$

The majority of CRC survivors die of other causes. ${ }^{92}$ Consequently, care for general medical and other preventive health issues should be of equal importance in the context of cancer care. A meta-analysis undertaken by Renehan et $\mathrm{al}^{93}$ estimated that only a small proportion of the survival benefit of intensive surveillance was due to curative treatment of recurrence, hypothesizing that the majority was probably due to the effect of more regular and intense contact facilitating detection and management of comorbidities, dietary and lifestyle changes, and psychological support and wellbeing. Increased follow-up also provides the opportunity for immunization and detecting and treating infections, which can be an issue for cancer survivors because of immune suppression associated with some cancer treatments. ${ }^{30}$

\section{Care coordination}

From 2015, hospital cancer programs accredited by the American College of Surgeons will be required to develop and disseminate survivorship care plans for all patients. ${ }^{94}$ As discussed previously, these care plans allow for the coordination of follow-up care between different providers across the areas of surveillance, intervention, and prevention. It is likely that facilitating good communication between oncology and primary care providers will result in greater continuity of care and improved patient outcomes. Nevertheless, definitive data supporting the benefits of survivorship care plans are lacking.

Cancer Care Ontario conducted a review of models of care in cancer survivorship in 2012. ${ }^{95}$ The authors report that there are few studies involving randomized comparisons between distinct model types, and that the quality and completeness of reporting is uneven. In colon cancer, one study found that there were no significant differences between survivors followed by a community-based family physician and those followed by an institutional-based specialist for rates of recurrence, time to detection of recurrence, rates of death, or physical, psychosocial, or quality of life components. ${ }^{96}$ Institution-based nurse-coordinated follow-up is another alternative that has been shown to be successful in breast cancer. ${ }^{97}$ A nurse-led survivorship care package is currently being evaluated in a randomized controlled trial for CRC survivors in Australia. ${ }^{98}$ 


\section{Future perspectives}

The goal of developing clinical practice guidelines is to improve the quality of health care by identifying and promoting the adoption of the best health care practices. ${ }^{86}$ The process of developing guidelines also reveals limitations of the existing evidence base and thus directions for future research. This article has highlighted aspects of CRC survivorship care where stronger evidence is needed to optimize surveillance, intervention, and secondary prevention. In particular, further work is needed to identify the most effective and cost-effective models of follow-up care to meet the needs of the growing number of CRC survivors.

In order for the growing evidence base to translate into improved outcomes for patients, care must be optimized for all survivors regardless of age, socioeconomic or cultural background, and geographical location. The literature certainly suggests that there is room for improvement, with variation in the application of guidelines noted in a number of areas of follow-up care. ${ }^{99-102}$ One of the key difficulties clinicians face is interpreting and applying literature that quickly becomes out of date relative to the available medical technology. ${ }^{52}$ However, rapid technological evolution also has its benefits. Strides are currently being made in identifying biomarkers that will better identify and target patients at greatest risk of recurrence. ${ }^{103}$ While recurrence will remain a key element of follow-up care, shifting the focus to incorporate the range of survivorship issues will also be important for ensuring widespread support and policy implementation in all areas of quality care.

\section{Acknowledgment}

Many thanks to Ivana Durcinoska for her assistance with literature searching.

\section{Disclosure}

The authors declare that there are no conflicts of interest.

\section{References}

1. International Agency for Research on Cancer. GLOBOCAN 2012: Estimated cancer incidence, mortality and prevalence worldwide in 2012. Lyon: IARC; 2013. Available from: http://globocan.iarc.fr/Pages/ fact_sheets_cancer.aspx. Accessed July 30, 2014.

2. Boyle P, Leon ME. Epidemiology of colorectal cancer. Br Med Bull. 2002;64:1-25.

3. United Nations. World Population Ageing: 1950-2050. Department of Economic and Social Affairs/Population Division. New York: United Nations; 2002.

4. Rutter CM, Johnson EA, Feuer EJ, Knudsen AB, Kuntz KM, Schrag D. Secular trends in colon and rectal cancer relative survival. J Natl Cancer Inst. 2013;105(23):1806-1813.
5. Institute of Medicine and National Research Council. From Cancer Patient to Cancer Survivor: Lost in Transition. Washington: The National Academies Press; 2005.

6. Denlinger CS, Barsevick AM. The challenges of colorectal cancer survivorship. J Natl Compr Canc Netw. 2009;7(8):883-894.

7. Richardson A, Addington-Hall J, Amir Z, et al. Knowledge, ignorance and priorities for research in key areas of cancer survivorship: findings from a scoping review. Br J Cancer. 2011;105 Suppl 1: S82-S94.

8. McCabe MS, Bhatia S, Oeffinger KC, et al. American Society of Clinical Oncology statement: achieving high-quality cancer survivorship care. J Clin Oncol. 2013;31(5):631-640.

9. Cowens-Alvarado R, Sharpe K, Pratt-Chapman M, et al. Advancing survivorship care through the National Cancer Survivorship Resource Center: developing American Cancer Society guidelines for primary care providers. CA Cancer J Clin. 2013;63(3):147-150.

10. Buie WD, Attard JA. Follow-up recommendations for colon cancer. Clin Colon Rectal Surg. 2005;18(3):232-243.

11. Meyerhardt JA, Mangu PB, Flynn PJ, et al. Follow-up care, surveillance protocol, and secondary prevention measures for survivors of colorectal cancer: American Society of Clinical Oncology clinical practice guideline endorsement. J Clin Oncol. 2013;31(35):4465-4470.

12. Hellinger MD, Santiago CA. Reoperation for recurrent colorectal cancer. Clin Colon Rectal Surg. 2006;19(4):228-236.

13. Rudmik LR, Buie WD, Heine JA. Reoperation for intraluminal rectal cancer recurrence. Dis Colon Rectum. 2005;48(9):1752-1754.

14. Manfredi S, Bouvier AM, Lepage C, Hatem C, Dancourt V, Faivre J. Incidence and patterns of recurrence after resection for cure of colonic cancer in a well defined population. Br J Surg. 2006;93(9): 1115-1122.

15. Bouvier AM, Latournerie M, Jooste V, Lepage C, Cottet V, Faivre J. The lifelong risk of metachronous colorectal cancer justifies long-term colonoscopic follow-up. Eur J Cancer. 2008;44(4): 522-527.

16. Lynch HT, Smyrk TC, Watson P, et al. Genetics, natural history, tumor spectrum, and pathology of hereditary nonpolyposis colorectal cancer: an updated review. Gastroenterology. 1993;104(5):1535-1549.

17. Wood ME, Vogel V, Ng A, Foxhall L, Goodwin P, Travis LB. Second malignant neoplasms: assessment and strategies for risk reduction. J Clin Oncol. 2012;30(30):3734-3745.

18. Andre T, Boni C, Navarro $M$, et al. Improved overall survival with oxaliplatin, fluorouracil, and leucovorin as adjuvant treatment in stage II or III colon cancer in the MOSAIC trial. J Clin Oncol. 2009;27(19):3109-3116.

19. Birgisson H, Pahlman L, Gunnarsson U, Glimelius B. Occurrence of second cancers in patients treated with radiotherapy for rectal cancer. J Clin Oncol. 2005;23(25):6126-6131.

20. Taylor GW, Jayne DG, Brown SR, et al. Adhesions and incisional hernias following laparoscopic versus open surgery for colorectal cancer in the CLASICC trial. Br J Surg. 2010;97(1):70-78.

21. Carne PW, Robertson GM, Frizelle FA. Parastomal hernia. Br J Surg. 2003;90(7):784-793.

22. Knowles G, Haigh R, McLean C, Phillips HA, Dunlop MG, Din FV. Long term effect of surgery and radiotherapy for colorectal cancer on defecatory function and quality of life. Eur J Oncol Nurs. 2013;17(5):570-577.

23. Birgisson H, Pahlman L, Gunnarsson U, Glimelius B. Late adverse effects of radiation therapy for rectal cancer - a systematic overview. Acta Oncol. 2007;46(4):504-516.

24. Harrington CB, Hansen JA, Moskowitz M, Todd BL, Feuerstein M. It's not over when it's over: long-term symptoms in cancer survivors a systematic review. Int J Psychiatry Med. 2010;40(2):163-181.

25. Thong MSY, Mols F, Wang XS, Lemmens VEPP, Smilde TJ, Van De Poll-Franse LV. Quantifying fatigue in (long-term) colorectal cancer survivors: a study from the population-based patient reported outcomes following initial treatment and long term evaluation of survivorship registry. Eur J Cancer. 2013;49(8):1957-1966. 
26. Land SR, Kopec JA, Cecchini RS, et al. Neurotoxicity from oxaliplatin combined with weekly bolus fluorouracil and leucovorin as surgical adjuvant chemotherapy for stage II and III colon cancer: NSABP C-07. J Clin Oncol. 2007;25(16):2205-2211.

27. Janelsins MC, Kohli S, Mohile SG, Usuki K, Ahles TA, Morrow GR. An update on cancer- and chemotherapy-related cognitive dysfunction: current status. Semin Oncol. 2011;38(3):431-438.

28. Koch L, Jansen L, Brenner H, Arndt V. Fear of recurrence and disease progression in long-term ( $>5$ years) cancer survivors - a systematic review of quantitative studies. Psychooncology. 2013;22(1):1-11.

29. Thewes B, Butow P, Bell ML, et al. Fear of cancer recurrence in young women with a history of early-stage breast cancer: a cross-sectional study of prevalence and association with health behaviours. Support Care Cancer. 2012;20(11):2651-2659.

30. National Comprehensive Cancer Network (NCCN). NCCN Clinical Practice Guidelines in Oncology: Survivorship. Version 2. Fort Washington: NCCN; 2014.

31. Zucca AC, Boyes AW, Linden W, Girgis A. All's well that ends well? Quality of life and physical symptom clusters in long-term cancer survivors across cancer types. J Pain Symptom Manage. 2012;43(4): $720-731$.

32. Stein KD, Syrjala KL, Andrykowski MA. Physical and psychological long-term and late effects of cancer. Cancer. 2008;112 Suppl 11:2577-2592.

33. de Boer AG, Taskila T, Ojajarvi A, van Dijk FJ, Verbeek JH. Cancer survivors and unemployment: a meta-analysis and meta-regression. JAMA. 2009;301(7):753-762.

34. Wells M, Williams B, Firnigl D, et al. Supporting 'work-related goals' rather than 'return to work' after cancer? A systematic review and meta-synthesis of 25 qualitative studies. Psychooncology. 2013;22(6):1208-1219.

35. Sideris L, Zenasni F, Vernerey D, et al. Quality of life of patients operated on for low rectal cancer: impact of the type of surgery and patients' characteristics. Dis Colon Rectum. 2005;48(12):2180-2191.

36. Schneider EC, Malin JL, Kahn KL, Ko CY, Adams J, Epstein AM. Surviving colorectal cancer: patient-reported symptoms 4 years after diagnosis. Cancer. 2007;110(9):2075-2082.

37. Arndt V, Merx H, Stegmaier C, Ziegler H, Brenner H. Quality of life in patients with colorectal cancer 1 year after diagnosis compared with the general population: a population-based study. J Clin Oncol. 2004;22(23):4829-4836.

38. Rauch P, Miny J, Conroy T, Neyton L, Guillemin F. Quality of life among disease-free survivors of rectal cancer. J Clin Oncol. 2004;22(2): 354-360.

39. Stein KB, Snyder CF, Barone BB, et al. Colorectal cancer outcomes, recurrence, and complications in persons with and without diabetes mellitus: a systematic review and meta-analysis. Dig Dis Sci. 2010;55(7): 1839-1851.

40. Mao JJ, Armstrong K, Bowman MA, Xie SX, Kadakia R, Farrar JT. Symptom burden among cancer survivors: impact of age and comorbidity. J Am Board Fam Med. 2007;20(5):434-443.

41. Cheng KKF, Lee DTF. Effects of pain, fatigue, insomnia, and mood disturbance on functional status and quality of life of elderly patients with cancer. Crit Rev Oncol Hematol. 2011;78(2):127-137.

42. Earle C, Annis R, Sussman J, et al. Follow-up Care, Surveillance Protocol, and Secondary Prevention Measures for Survivors of Colorectal Cancer. Toronto: Cancer Care Ontario; 2012.

43. National Comprehensive Cancer Network (NCCN). NCCN Clinical Practice Guidelines in Oncology: Colon Cancer. Version 2. Fort Washington: NCCN; 2015.

44. National Comprehensive Cancer Network (NCCN). NCCN Clinical Practice Guidelines in Oncology: Rectal Cancer. Version 2. Fort Washington: NCCN; 2015.

45. Labianca R, Nordlinger B, Beretta GD, et al. Early colon cancer: ESMO clinical practice guidelines for diagnosis, treatment and follow-up. Ann Oncol. 2013;24 Suppl 6:64-72.
46. Glimelius B, Tiret E, Cervantes A, Arnold D. Rectal cancer: ESMO clinical practice guidelines for diagnosis, treatment and follow-up. Ann Oncol. 2013;24 Suppl 6:81-88.

47. Poston GJ, Tait D, O'Connell S, Bennett A, Berendse S. Diagnosis and management of colorectal cancer: summary of NICE guidance. BMJ. 2011;343(7831):1010-1012.

48. Cancer Council Australia Colonoscopy Surveillance Working Party. Clinical Practice Guidelines for Surveillance Colonoscopy - In Adenoma Follow-Up; Following Curative Resection of Colorectal Cancer; and for Cancer Surveillance in Inflammatory Bowel Disease. Sydney: Cancer Council Australia; 2011

49. New Zealand Guidelines Group. Clinical Practice Guidelines for the Management of Early Colorectal Cancer. Wellington: New Zealand Guidelines Group; 2011.

50. Cairns SR, Scholefield JH, Steele RJ, et al. Guidelines for colorectal cancer screening and surveillance in moderate and high risk groups (update from 2002). Gut. 2010;59(5):666-689.

51. Watanabe T, Itabashi M, Shimada Y, et al. Japanese Society for Cancer of the Colon and Rectum (JSCCR) guidelines 2010 for the treatment of colorectal cancer. Int J Clin Oncol. 2012;17(1):1-29.

52. Young PE, Womeldorph CM, Johnson EK, et al. Early detection of colorectal cancer recurrence in patients undergoing surgery with curative intent: current status and challenges. J Cancer. 2014;5(4):262-271.

53. Fahy BN. Follow-up after curative resection of colorectal cancer. Ann Surg Oncol. 2014;2(3):738-746.

54. Tjandra JJ, Chan MKY. Follow-up after curative resection of colorectal cancer: a meta-analysis. Dis Colon Rectum. 2007;50(11):1783-1799.

55. Jeffery M, Hickey BE, Hider PN. Follow-up strategies for patients treated for non-metastatic colorectal cancer. Cochrane Database Syst Rev. 2007;1:CD002200.

56. Primrose JN, Perera R, Gray A, et al. Effect of 3 to 5 years of scheduled CEA and CT follow-up to detect recurrence of colorectal cancer: the FACS randomized clinical trial. JAMA. 2014;311(3):263-270.

57. Baca B, Beart RW Jr, Etzioni DA. Surveillance after colorectal cancer resection: a systematic review. Dis Colon Rectum. 2011;54(8): 1036-1048.

58. Schmoll HJ, Van cutsem E, Stein A, et al. ESMO Consensus Guidelines for management of patients with colon and rectal cancer. a personalized approach to clinical decision making. Ann Oncol. 2012;23(10): 2479-2516

59. Pacelli F, Tortorelli AP, Rosa F, et al. Locally recurrent rectal cancer: prognostic factors and long-term outcomes of multimodal therapy. Ann Surg Oncol. 2010;17(1):152-162.

60. Yang TX, Morris DL, Chua TC. Pelvic exenteration for rectal cancer: a systematic review. Dis Colon Rectum. 2013;56(4):519-531.

61. Young JM, Badgery-Parker T, Masya LM, et al. Quality of life and other patient-reported outcomes following exenteration for pelvic malignancy. Br J Surg. 2014;101(3):277-287.

62. Furman MJ, Lambert LA, Sullivan ME, Whalen GF. Rational follow-up after curative cancer resection. J Clin Oncol. 2013;31(9): $1130-1133$.

63. Rose J, Augestad KM, Cooper GS. Colorectal cancer surveillance: what's new and what's next? World J Gastroenterol. 2014;20(8): $1887-1897$.

64. Earle CC. Is more intensive surveillance really a good idea for high-risk patients with colorectal cancer? J Clin Oncol. 2014;32(14):1518.

65. Ku G, Tan IB, Yau T, et al. Management of colon cancer: resourcestratified guidelines from the Asian Oncology Summit 2012. Lancet Oncol. 2012;13(11):470-481.

66. Augestad KM, Rose J, Crawshaw B, Cooper G, Delaney C. Do the benefits outweigh the side effects of colorectal cancer surveillance? A systematic review. World J Gastrointest Oncol. 2014;6(5):104-111.

67. Hershman DL, Lacchetti C, Dworkin RH, et al. Prevention and management of chemotherapy-induced peripheral neuropathy in survivors of adult cancers: American Society of Clinical Oncology clinical practice guideline. J Clin Oncol. 2014;32(18):1941-1967. 
68. Bower JE, Bak K, Berger A, et al. Screening, assessment, and management of fatigue in adult survivors of cancer: an American Society of Clinical oncology clinical practice guideline adaptation. J Clin Oncol. 2014;32(17):1840-1850.

69. Andersen BL, DeRubeis RJ, Berman BS, et al. Screening, assessment, and care of anxiety and depressive symptoms in adults with cancer: an American Society of Clinical Oncology guideline adaptation. J Clin Oncol. 2014;32(15):1605-1619.

70. Turnbull G, Baldassarre F, Brown P, et al. Psychosocial Health Care for Cancer Patients and their Families. Toronto: Cancer Care Ontario; 2010.

71. Coleman R, Body J, Aapro M, Hadji P, Herrstedt J. Bone health in cancer patients: ESMO Clinical Practice Guidelines. Ann Oncol. 2014;25 Suppl 3:iii124-iii137.

72. Ripamonti CI, Santini D, Maranzano E, Berti M, Roila F, Group EGW. Management of cancer pain: ESMO Clinical Practice Guidelines. Ann Oncol. 2012;23 Suppl 7:139-154.

73. Cancer Journey Survivorship Expert Panel. Survivorship services for adult cancer populations: a pan-Canadian guideline. Curr Oncol. 2011;18:265-281.

74. National Comprehensive Cancer Network (NCCN). NCCN Clinical Practice Guidelines in Oncology: Survivorship. Version 1. Fort Washington: NCCN; 2013.

75. Campbell HS, Hall AE, Sanson-Fisher RW, Barker D, Turner D, Taylor-Brown J. Development and validation of the Short-Form Survivor Unmet Needs Survey (SF-SUNS). Support Care Cancer. 2014;22(4):1071-1079.

76. Avis NE, Smith KW, McGraw S, Smith RG, Petronis VM, Carver CS. Assessing quality of life in adult cancer survivors (QLACS). Qual Life Res. 2005;14(4):1007-1023.

77. Mitchell AJ. Screening for cancer-related distress: when is implementation successful and when is it unsuccessful? Acta Oncol. 2013;52(2):216-224.

78. Stanton AL. What happens now? Psychosocial care for cancer survivors after medical treatment completion. J Clin Oncol. 2012;30(11): 1215-1220.

79. Brown JC, Huedo-Medina TB, Pescatello LS, et al. The efficacy of exercise in reducing depressive symptoms among cancer survivors: a meta-analysis. PLoS One. 2012;7(1):30955.

80. Piet J, Wurtzen H, Zachariae R. The effect of mindfulness-based therapy on symptoms of anxiety and depression in adult cancer patients and survivors: a systematic review and meta-analysis. J Consult Clin Psychol. 2012;80(6):1007-1020.

81. Cramp F, Byron-Daniel J. Exercise for the management of cancerrelated fatigue in adults. Cochrane Database Syst Rev. 2012;11: CD006145.

82. Kangas M, Bovbjerg DH, Montgomery GH. Cancer-related fatigue: a systematic and meta-analytic review of non-pharmacological therapies for cancer patients. Psychol Bull. 2008;134(5):700-741.

83. Mishra SI, Scherer RW, Geigle PM, et al. Exercise interventions on health-related quality of life for cancer survivors. Cochrane Database Syst Rev. 2012;8:CD007566.

84. Espie CA, Fleming L, Cassidy J, et al. Randomized controlled clinical effectiveness trial of cognitive behavior therapy compared with treatment as usual for persistent insomnia in patients with cancer. $J$ Clin Oncol. 2008;26(28):4651-4658.

85. Butow P, Bell M, Smith A, et al. Conquer fear: protocol of a randomised controlled trial to reduce fear of cancer recurrence. BMC Cancer. 2013; 13(1):201.

86. Jacobsen PB. Clinical practice guidelines for the psychosocial care of cancer survivors: current status and future prospects. Cancer. 2009;115 Suppl 18:4419-4429.
87. Mewes JC, Steuten LM, Ijzerman MJ, van Harten WH. Effectiveness of multidimensional cancer survivor rehabilitation and cost-effectiveness of cancer rehabilitation in general: a systematic review. Oncologist. 2012;17(12):1581-1593.

88. Davies NJ, Batehup L, Thomas R. The role of diet and physical activity in breast, colorectal, and prostate cancer survivorship: a review of the literature. Br J Cancer. 2011;105 Suppl 1:S52-S73.

89. Schmid D, Leitzmann MF. Association between physical activity and mortality among breast cancer and colorectal cancer survivors: a systematic review and meta-analysis. Ann Oncol. 2014;25(7):1293-1311.

90. Ballard-Barbash R, Friedenreich CM, Courneya KS, Siddiqi SM, McTiernan A, Alfano CM. Physical activity, biomarkers, and disease outcomes in cancer survivors: a systematic review. J Natl Cancer Inst. 2012;104(11):815-840.

91. Walter V, Jansen L, Hoffmeister M, Brenner H. Smoking and survival of colorectal cancer patients: systematic review and meta-analysis. Ann Oncol. 2014;25(8):1517-1525.

92. Gross CP, Guo Z, McAvay GJ, Allore HG, Young M, Tinetti ME. Multimorbidity and survival in older persons with colorectal cancer. J Am Geriatr Soc. 2006;54(12):1898-1904.

93. Renehan AG, Egger M, Saunders MP, O’Dwyer ST. Impact on survival of intensive follow up after curative resection for colorectal cancer: systematic review and meta-analysis of randomised trials. $B M J$. 2002;324(7341):813-816.

94. Commission on Cancer. Cancer Program Standards 2012: Ensuring Patient-Centered Care. V1.2.1. Chicago: American College of Surgeons; 2014.

95. Sussman J, Souter LH, Grunfeld E, et al. Models of Care for Cancer Survivorship. Toronto: Cancer Care Ontario; 2012.

96. Wattchow DA, Weller DP, Esterman A, et al. General practice vs surgical-based follow-up for patients with colon cancer: randomised controlled trial. Br J Cancer. 2006;94(8):1116-1121.

97. Sheppard C, Higgins B, Wise M, Yiangou C, Dubois D, Kilburn S Breast cancer follow up: a randomised controlled trial comparing point of need access versus routine 6-monthly clinical review. Eur J Oncol Nurs. 2009;13(1):2-8.

98. Jefford M, Aranda S, Gough K, et al. Evaluating a nurse-led survivorship care package (SurvivorCare) for bowel cancer survivors: study protocol for a randomized controlled trial. Trials. 2013;14(1):260.

99. Carpentier MY, Vernon SW, Bartholomew LK, Murphy CC, Bluethmann SM. Receipt of recommended surveillance among colorectal cancer survivors: a systematic review. J Cancer Surviv. 2013;7(3):464-483.

100. Salz T, Woo H, Starr TD, Jandorf LH, DuHamel KN. Ethnic disparities in colonoscopy use among colorectal cancer survivors: a systematic review. J Cancer Surviv. 2012;6(4):372-378.

101. Salz T, Oeffinger KC, McCabe MS, Layne TM, Bach PB. Survivorship care plans in research and practice. CA Cancer J Clin. 2012;62(2):101-117.

102. Snyder CF, Frick KD, Herbert RJ, et al. Quality of care for comorbid conditions during the transition to survivorship: differences between cancer survivors and noncancer controls. J Clin Oncol. 2013;31(9):1140-1148.

103. Ganepola GA, Nizin J, Rutledge JR, Chang DH. Use of blood-based biomarkers for early diagnosis and surveillance of colorectal cancer. World J Gastrointest Oncol. 2014;6:83-97.

104. National Comprehensive Cancer Network (NCCN). NCCN Clinical Practice Guidelines in Oncology: Genetic/familial high-risk assessment: colorectal. Version 2. Fort Washington: NCCN; 2014. 


\section{Publish your work in this journal}

Patient Related Outcome Measures is an international, peer-reviewed, open access journal focusing on treatment outcomes specifically relevant to patients. All aspects of patient care are addressed within the journal and practitioners from all disciplines are invited to submit their work as well as healthcare researchers and patient support groups. The manuscript management system is completely online and includes a very quick and fair peer-review system. Visit http:// www.dovepress.com/testimonials.php to read real quotes from published authors

Submit your manuscript here: http://www.dovepress.com/patient-related-outcome-measures-journal 